\title{
Working memory, inhibitory control, and reading disability
}

\author{
PENNY CHIAPPE \\ University of British Columbia, Vancouver, British Columbia, Canada \\ LYNN HASHER \\ Duke University, Durham, North Carolina \\ and \\ LINDA S. SIEGEL \\ University of British Columbia, Vancouver, British Columbia, Canada
}

\begin{abstract}
The relationships among working memory, inhibitory control, and reading skills were studied in 966 individuals, 6-49 years old. In addition to a standardized measure of word recognition, they received a working memory (listening span) task in the standard, blocked format (three sets containing two-, three-, or four-item trials) or in a mixed format (three sets each containing two-, three-, and four-item trials) to determine whether scores derived from the standard format are influenced by proactive interference. Intrusion errors were investigated in order to determine whether deficits in working memory were associated with the access, deletion, or restraint functions of inhibitory control. The results indicated that deficits in working memory were characteristic of individuals with reading disabilities at all ages. These deficits may be associated with the access and restraint functions of inhibition. Working memory skills increased until the age of 19 . The blocked format showed a gradual decline in adulthood whereas the mixed format did not. The different patterns suggest that the decline in working memory skills associated with aging may result from growing inefficiencies in inhibitory control, and not diminished capacity.
\end{abstract}

Working memory refers to the cognitive processes involved in the temporary storage of information while an individual is simultaneously processing incoming information or retrieving information from long-term storage. As such, it is thought to underlie a number of cognitive processes, such as reading, problem solving, and learning (see, e.g., Baddeley, 1983, 1986; Daneman \& Carpenter, 1980).

Working memory has been conceptualized as consisting of a central processor, known as the central executive, which controls a number of subsidiary systems that operate on and store specific information about the items being processed (Baddeley, 1983). An important feature of working memory is that it has limited capacity. Its limited capacity may be considered a limited pool of attentional resources or a finite work space that must be shared between processing and data storage (Tirre \& Peña, 1992).

This article was written while P.C. was a postdoctoral fellow at the University of British Columbia. This research was supported by a grant from the U.S. National Institute on Aging to L.H. and a grant from the Natural Science and Engineering Research Council (NSERC) of Canada to L.S.S. The authors wish to thank Anna Maria Macri for her assistance in coding errors, as well as the individuals who participated in this study. We are also grateful for the insightful comments provided by Dan Chiappe, Morton Ann Gernsbacher, and two anonymous reviewers. Correspondence should be addressed to P. Chiappe, School of Education, E274 Thompson Hall, SUNY at Fredonia, Fredonia, NY 14063 (e-mail: chiappep@fredonia.edu).
From this perspective, when more demands are placed on the central executive, fewer cognitive resources remain available for the subsidiary systems.

In 1980, Daneman and Carpenter introduced the reading span task as a measure of functional working memory available for reading. This task was designed to assess both the storage and processing components of working memory. In the reading span task and its variants, participants read or listened to a series of unrelated sentences and comprehended each sentence while preparing to recall the final word of each sentence at the end of the set. As the number of sentences increased, demands on working memory were also assumed to increase.

An important contribution of Daneman and Carpenter's (1980) reading span measure is its capacity to assess both the storage and the processing components of working memory. Given the limited capacity, individuals who experience difficulties processing the primary task (e.g., reading or listening comprehension) would need to devote more resources or capacity to processing sentences. Consequently, they would have fewer resources available to maintain the target words in memory. Conversely, individuals who are skilled at processing sentences are expected to have greater resources available for the storage task.

In fact, working memory capacity varies as a function of individual differences and age (see, e.g., Daneman \& Carpenter, 1980; Gick, Craik, \& Morris, 1988; Hasher \& Zacks, 1988; Siegel \& Ryan, 1988). For example, individ- 
uals with reading disabilities experience significant difficulties with working memory (Siegel, 1994; Siegel \& Linder, 1984; Siegel \& Ryan, 1988; Swanson, 1993, 1994). Similar difficulties in working memory have been reported for disabled readers in Chinese (So \& Siegel, 1997), Hebrew (Geva \& Siegel, in press), Italian (De Beni, Palladino, Pazzaglia, \& Cornoldi, 1998), and Portuguese (Da Fontoura \& Siegel, 1995).

In addition, working memory capacity has been shown to vary across the lifespan. For example, working memory performance has been shown to increase throughout childhood and adolescence, and then decline gradually through adulthood until age 50 (Siegel, 1994). According to some developmental theorists, growth in functional working memory through childhood is the result of increases in working memory capacity (e.g., Case, Kurland, \& Goldberg, 1982; Hitch \& Halliday, 1983). Similarly, according to the reduced capacity view, the resources individuals have available for the storage and processing of information diminish as they grow older. As a result, older individuals demonstrate performance decrements on measures of working memory (see, e.g., Babcock \& Salthouse, 1990; Campbell \& Charness, 1990; Gick et al., 1988; Light \& Anderson, 1985; Morris, Gick, \& Craik, 1988; Salthouse \& Babcock, 1991; Wingfield, Stine, Lahar, \& Aberdeen, 1988). Thus, changes in working memory performance across the lifespan have been attributed to changes in working memory capacity.

Recently, an alternative interpretation of the data showing reductions of working memory span with age and with reading skill has been offered by Hasher and her colleagues (Hasher, Stoltzfus, Rumpa, \& Zacks, 1991; Hasher \& Zacks, 1988; Hasher, Zacks, \& May, 1999) and by Gernsbacher and her colleagues (Gernsbacher, 1990; Gernsbacher \& Faust, 1991). These researchers have hypothesized that age-related cognitive deficits, and possibly individual differences related to reading skill, may result from inefficient inhibitory control of attention. For example, comparisons of more and less skilled universityage readers revealed that less skilled readers were less efficient at rejecting inappropriate meanings of ambiguous words and incorrect forms of homophones, ignoring words and pictures, revising incorrect inferences, and ignoring words and pictures (Gernsbacher \& Faust, 1991; Gernsbacher, Varner, \& Faust, 1990; Whitney, Ritchie, \& Clark, 1991). Similarly, less skilled readers tended to accept meanings of homonyms that were not implied by the sentence context more slowly than more skilled readers (Gernsbacher \& Robertson, 1995). Because the less skilled readers activated contextually appropriate information with greater strength than the more skilled readers, Gernsbacher attributed the less skilled readers' poorer reading comprehension to less efficient suppression mechanisms.

Relatedly, declines in working memory associated with aging have been attributed to decreases in the ability to suppress irrelevant or no-longer-relevant information rather than decreases in working memory capacity. For example, the phenomenon of negative priming is seen in tasks requiring responses to target items in the presence of distractors. Responses to items that have been switched from distractors to targets tend to be slower as a result of inhibition. Although young adults tend to show negative priming, older adults often do not (Kane, May, Hasher, \& Rahhal, 1997; May, Kane, \& Hasher, 1995; Stoltzfus, Hasher, Zacks, Ulivi, \& Goldstein, 1993). Similarly, investigations using garden-path stories revealed that although older adults were as likely as young adults to encode the correct interpretation, they were more likely to maintain the original, incorrect interpretation (Hamm \& Hasher, 1992). The failure to inhibit the initial, incorrect interpretation results in difficulties in recalling the stories (Zacks \& Hasher, 1988). Thus, the decline in working memory associated with aging may result from deficits in the inability to clear from working memory information that is irrelevant or information that is no longer relevant.

There are three ways in which inhibition may control the contents of working memory (Hasher et al., 1999). These functions are access, deletion, and restraint. Inhibition may control access to working memory by preventing any activated but goal-irrelevant information from entering working memory. In this manner, inhibition restricts access to working memory to goal-relevant information. Inhibition also controls the contents of working memory by deleting or suppressing the activation of irrelevant information or information that was once relevant and is no longer relevant. Thus, the deletion function of inhibition removes irrelevant information from the working memory buffer. Failures of the deletion function would lead to proactive interference, a disrupted pattern of recall produced by competition among relevant and irrelevant events at retrieval. Finally, inhibitory processes serve a restraining function by preventing strong responses from immediately seizing control of thought and action effectors so that other, less probable, responses can be considered. Thus, the restraining function of inhibition suppresses erroneous interpretations of text and language. Taken together, these functions ensure that information in the memory buffer is restricted to goal-relevant information.

Hasher and colleagues (Hasher et al., 1999) suggested that the decline in working memory performance associated with aging is caused in part by diminished inhibitory control. Older adults tend to show greater proactive interference than younger adults (Kane \& Hasher, 1996). Because older adults are more susceptible to proactive interference, their working memory spans may be reduced. Thus, age differences in working memory spans may result from diminished inhibitory control with aging. According to this view, if the influence of proactive interference can be reduced, age differences in working memory span should be diminished. In fact, Hasher and her colleagues eliminated age differences in working memory span by changing the usual span procedure so as to reduce proactive interference (May, Kane, Hasher, \& Valenti, 1996). One way to reduce proactive interference involved increasing the distinctiveness of each trial in a working memory task by administering a unique, nonver- 
bal 90-sec distractor task after each trial. After the distractor task had been administered, older adults' working memory spans were as large as the spans of younger adults. These findings cannot be accounted for by limited capacity models alone. Therefore, failures of inhibitory control do seem to play an important role in working memory performance, at least that of older adults.

The central purpose of the current study was to examine the extent to which the inhibitory control hypothesis may account for differences in working memory based on age and reading skill. The working memory performance of people who ranged in age from 6 to 49 was studied. These people had been given one of two versions of the working memory task. In Experiment 1, participants were given the listening span task in the standard blocked procedure, whereas a mixed procedure was used in Experiment 2. Deficit in inhibitory control was assessed through the analysis of errors. Errors associated with aging have been hypothesized to reflect failures of the deletion and restraining functions of inhibitory control. Therefore, intrusion errors that were either previous targets (reflecting failures of deletion) or new words (reflecting failures of restraint) were hypothesized to increase with age.

In addition to examining the relationship between age, error patterns, and span scores, the present study was able to assess this relationship for people with and without reading disabilities. In the current study, participants with reading disabilities were characterized by deficits in word recognition. However, in much of the research investigating the relationship between inhibitory control and reading skill, the less skilled readers were not individuals with reading disabilities. They were university students who read within the normal range of adult reading skill (see, e.g., Gernsbacher \& Faust, 1991; Gernsbacher \& Robertson, 1995; Gernsbacher et al., 1990; Whitney et al., 1991). Although deficits in suppression mechanisms interfered with reading comprehension among normal adult readers, there is little evidence that impaired inhibitory control is related to the deficient word recognition skills associated with reading disability. In fact, there is considerable evidence that impairments in phonological processing inhibit the development of fluent word recognition among disabled readers of all ages (e.g., Bruck, 1990, 1992; Bruck \& Treiman, 1990; Perfetti, 1985; Rack, Snowling, \& Olson, 1992; Share, 1995; Siegel \& Ryan, 1988; Stanovich \& Siegel, 1994). Consequently, individuals with reading disabilities tend to have limited automaticity in word recognition and are dependent on slow, capacity-draining word recognition processes (Stanovich, 1986). Although limited working memory capacity may interfere with the slow, demanding processes involved in word recognition for disabled readers, impairments in inhibitory control may also contribute to poor word recognition. For example, because disabled readers are less skilled at applying appropriate grapheme-phoneme correspondences (Chiappe \& Siegel, 1999), disabled readers must inhibit inappropriate grapheme-phoneme correspondences. Failures to inhibit incorrect candidate pronunciations may further impair performance in word recognition. Therefore, it is possible that deficits in inhibitory control interfere with the word recognition of disabled readers.

\section{EXPERIMENT 1}

\section{Method}

\section{Participants}

The analyses presented here combined the data from adults and children who participated in one of a series of published and unpublished studies (e.g., Chiappe \& Siegel, 1999; Shafrir \& Siegel, 1992; Siegel, 1994). This total sample included 665 individuals351 skilled readers and 314 individuals with reading disabilities. Participants from these studies had been recruited from schools, universities, colleges, and community agencies; some were volunteers from the community. The sample was predominantly middle class. All participants had been educated in English. Participants were classified as disabled readers if they had scores below the 26th percentile on the Wide Range Achievement Test (WRAT; Jastak \& Jastak, 1978; WRAT-R, Jastak \& Wilkinson, 1984; WRAT-3, Wilkinson, 1994) and an IQ $>79$ on an abbreviated version of the Wechsler Intelligence for Children (WISC-R; Sattler, 1982; Weschler, 1974) or the Wechsler Adult Intelligence ScaleRevised (WAIS-R; Silverstein, 1982; Weschler, 1974) that included the Vocabulary and the Block Design subtests.

Participants were arbitrarily divided into five age groups: $6-9$, $10-19,20-29,30-39$, and $40-49$. The numbers of skilled readers (first number in parentheses) and disabled readers (second number in parentheses) within each age group were: $6-9(98,108), 10-19$ $(85,68), 20-29(99,81), 30-39(43,45)$, and $40-49(26,12)$.

\section{Reading Tests}

The reading subtest of the Wide Range Achievement Test (WRAT, WRAT-R, or WRAT-3) tested individuals' ability to read single words in isolation.

\section{Working Memory}

The blocked design of the listening span task was based on the procedure developed by Daneman and Carpenter (1980). The experimenter read to participants sentences each of which was missing its final word. Participants supplied the missing word and attempted to repeat all the set's missing words on completion of the set. Sets contained two, three, or four sentences. Each set size, or level, contained three trials. To reduce difficulties in word retrieval, the sentences were selected so that the final word was virtually predetermined. None of the participants experienced difficulties in providing the final word. Examples of sentences were as follows: "In a baseball game, the pitcher throws the __."; "On my two hands, I have ten _.." Participants then attempted to repeat the two words that they had selected, in this case, ball and fingers. The task was discontinued when an individual failed all three items at a given level.

An absolute span score was calculated for each participant using the procedure developed by Engle and his colleagues (Engle, Cantor, \& Carullo, 1992; Engle, Nations, \& Cantor, 1990). To calculate the absolute span score, the number of words recalled on perfectly recalled trials was summed. In perfectly recalled trials, participants were not penalized for recalling the words in an incorrect order. Thus, if a participant perfectly recalled all three trials of Set Length 2, two trials of Set Length 3, and recalled none of the trials with a set length of four perfectly, the absolute span score would be 12. The highest possible absolute span score was 27.

\section{Error Analyses}

Because the purpose of this study was to evaluate the role of inhibition in working memory, two types of errors, no responses (or 
Table 1

Mean Span Scores, Error Rates, and Standard Deviations on the Blocked and Mixed Designs of the Working Memory Task as a Function of Age and Reading Skill

\begin{tabular}{|c|c|c|c|c|c|c|c|c|c|c|c|c|c|c|c|c|c|c|c|c|c|c|c|c|}
\hline \multirow[b]{3}{*}{ Age } & \multicolumn{4}{|c|}{ Absolute Span } & \multicolumn{4}{|c|}{ No Response } & \multicolumn{4}{|c|}{ Total Intrusions } & \multicolumn{4}{|c|}{$\begin{array}{c}\text { Current } \\
\text { Nonfinal Intrusions }\end{array}$} & \multicolumn{4}{|c|}{$\begin{array}{c}\text { Previous } \\
\text { Final Intrusions }\end{array}$} & \multicolumn{4}{|c|}{$\begin{array}{l}\text { Extraneous } \\
\text { Intrusions }\end{array}$} \\
\hline & \multicolumn{2}{|c|}{$\begin{array}{l}\text { Skilled } \\
\text { Readers }\end{array}$} & \multicolumn{2}{|c|}{$\begin{array}{l}\text { Disabled } \\
\text { Readers }\end{array}$} & \multicolumn{2}{|c|}{$\begin{array}{l}\text { Skilled } \\
\text { Readers }\end{array}$} & \multicolumn{2}{|c|}{$\begin{array}{l}\text { Disabled } \\
\text { Readers }\end{array}$} & \multicolumn{2}{|c|}{$\begin{array}{l}\text { Skilled } \\
\text { Readers }\end{array}$} & \multicolumn{2}{|c|}{$\begin{array}{l}\text { Disabled } \\
\text { Readers }\end{array}$} & \multicolumn{2}{|c|}{$\begin{array}{l}\text { Skilled } \\
\text { Readers }\end{array}$} & \multicolumn{2}{|c|}{$\begin{array}{l}\text { Disabled } \\
\text { Readers }\end{array}$} & \multicolumn{2}{|c|}{$\begin{array}{l}\text { Skilled } \\
\text { Readers }\end{array}$} & \multicolumn{2}{|c|}{$\begin{array}{l}\text { Disabled } \\
\text { Readers }\end{array}$} & \multicolumn{2}{|c|}{$\begin{array}{l}\text { Skilled } \\
\text { Readers }\end{array}$} & \multicolumn{2}{|c|}{$\begin{array}{l}\text { Disabled } \\
\text { Readers }\end{array}$} \\
\hline & $M$ & $S D$ & $M$ & $S D$ & $M$ & $S D$ & $M$ & $S D$ & $M$ & $\overline{S D}$ & $M$ & $S D$ & $M$ & $S D$ & $M$ & $S D$ & $M$ & $S D$ & $M$ & $S D$ & $M$ & $S D$ & $M$ & $S D$ \\
\hline \multicolumn{25}{|c|}{ Blocked Design } \\
\hline & & & & & & & & & & & & & & & & & & & & & & & & \\
\hline & & & & & & .31 & & .2 & & & & & & & & & & & & & & & 0.19 & \\
\hline & & 6.3 & 12.5 & 61 & .79 & .30 & .76 & .24 & & & & & & 0. & & & & & 0.4 & & 05 & & 0.21 & 0. \\
\hline & & 6.7 & 12.8 & 5.21 & .73 & .27 & .80 & .19 & & & & & 0.7 & 0.8 & & & & & 0.2 & & 0.12 & 0.32 & 0.11 & 0.3 \\
\hline & & 7.23 & & 6.88 & .78 & .27 & .81 & .17 & 0.92 & 1.09 & 2.0 & 1.65 & 0.73 & 0.92 & 1.33 & & 0.19 & 0.40 & .33 & & 0 & 0 & .33 & 0.4 \\
\hline \multicolumn{25}{|c|}{ Mixed Design } \\
\hline & & & & & & .19 & & .20 & & & & & & 1. & & & & & & & & & & \\
\hline & & & & & & .27 & & .2 & & & & & & 2. & & & & & & & & & & \\
\hline & & & & & .68 & .24 & .64 & .25 & & 1.2 & 4.0 & & & 0. & & & & & & & & & & \\
\hline & & & & & .66 & .31 & .6 & .31 & & 1.7 & 3. & & 0.6 & 0.8 & & & & & & & & & 0.19 & \\
\hline & & & & 5.13 & .67 & .31 & .60 & .19 & 1.10 & 1.00 & 5.40 & 3.78 & 0.60 & 0.70 & 3.60 & 2.70 & 0.30 & 0.68 & 1.40 & 1.14 & 0.20 & 0.42 & 0.40 & 0.5 \\
\hline
\end{tabular}

omissions) and intrusion errors, were analyzed. Omissions were analyzed as a proportion of all errors. That is, the number of items for which the participant did not provide a response was divided by the total number of target words that were not recalled correctly. Intrusion errors occurred when participants misrecalled a target word and provided another word as the response. Three categories of mutually exclusive errors were considered. The first type of error, current nonfinal (CNF) intrusions, were errors in which the response was a word from the current trial but was not one of the target words. CNF intrusions reflected deficient inhibition that resulted in increased entry into working memory of irrelevant information. The second type of error, previous (P) intrusions, were responses in which either target words or nonfinal words from earlier trials were recalled. Previous intrusions reflect proactive interference that may result from the failure to inhibit information once it has become irrelevant. Finally, extraneous $(E)$ intrusions were errors in which the response was a word that had not been presented in the current or previous trials. Extraneous intrusions may reflect deficiencies in the restraining function of inhibition. The total number of intrusion errors and the raw score of each type of error were used as dependent variables.

\section{Results}

The results for the absolute span scores are shown in Figure 1 and the two left columns in the top portion of Table 1. A 5 (age) $\times 2$ (reading group) analysis of variance (ANOVA) indicated significant main effects of age $[F(4,655)=104.21, p<.001]$ and reading group $[F(4,655)=33.40, p<.001]$. The interaction between age and reading group was also significant $[F(4,655)=$ $3.77, p<.01]$. This blocked version of the working memory task revealed an increase in working memory capacity for both skilled and disabled readers until age 20 , at which point scores started to decline. This pattern of performance is consonant with the literature (Siegel, 1994). Individual comparisons for each age group ( $t$ tests) indicated that skilled readers had higher scores than disabled readers at each age level. In general, there were significant differences between the first three adjacent age groups (under 10, 10-19, and 20-29). The scores of children under 10 were significantly lower than those of the other groups, while the scores of the 10-19 age group were significantly higher than those of all other groups. The interaction was determined both by a greater increase in working memory performance for skilled readers than for disabled readers as they went from the youngest age group to the 10-19 group, and by a decline in performance seen in disabled readers in the 40-49 age group. This decline was not shown by skilled readers.

\section{Error Analyses}

No responses. The proportion of no responses is shown in the top half of Table 1 . All dependent variables were analyzed using 5 (age) $\times 2$ (reading group) ANOVAs. The rate of no responses differed significantly among the five age groups $[F(4,624)=8.59, p<.001]$. However, neither the main effect of reading group $[F(1,624)<$ 1, n.s.] nor the age $\times$ reading group interaction was significant $[F(4,419)<1$, n.s.]. Post hoc comparisons (Fischer's PLSD) indicated that children under 10 committed more no response errors than did all groups of older participants; there were no differences in omission rates as a function of reading skill.

Total intrusions. The mean number of intrusion errors is shown in the top half of Table 1. Skilled readers produced fewer intrusion errors than disabled readers $[F(1,655)=14.60, p<.001]$. Although there was no effect of age $[F(4,655)=2.18$, n.s. $]$, the age $\times$ reading group interaction was significant $[F(4,655)=3.40, p<.01]$. The interaction was determined by a decline in intrusions produced by skilled readers between the ages of 10 and 29 that was not shown by disabled readers.

Current nonfinal intrusions. The mean number of CNF intrusions is shown in the top half of Table 1. There was a significant main effect of age $[F(4,655)=2.71, p<$ .05]. Post hoc comparisons (Fischer's PLSD) indicated 


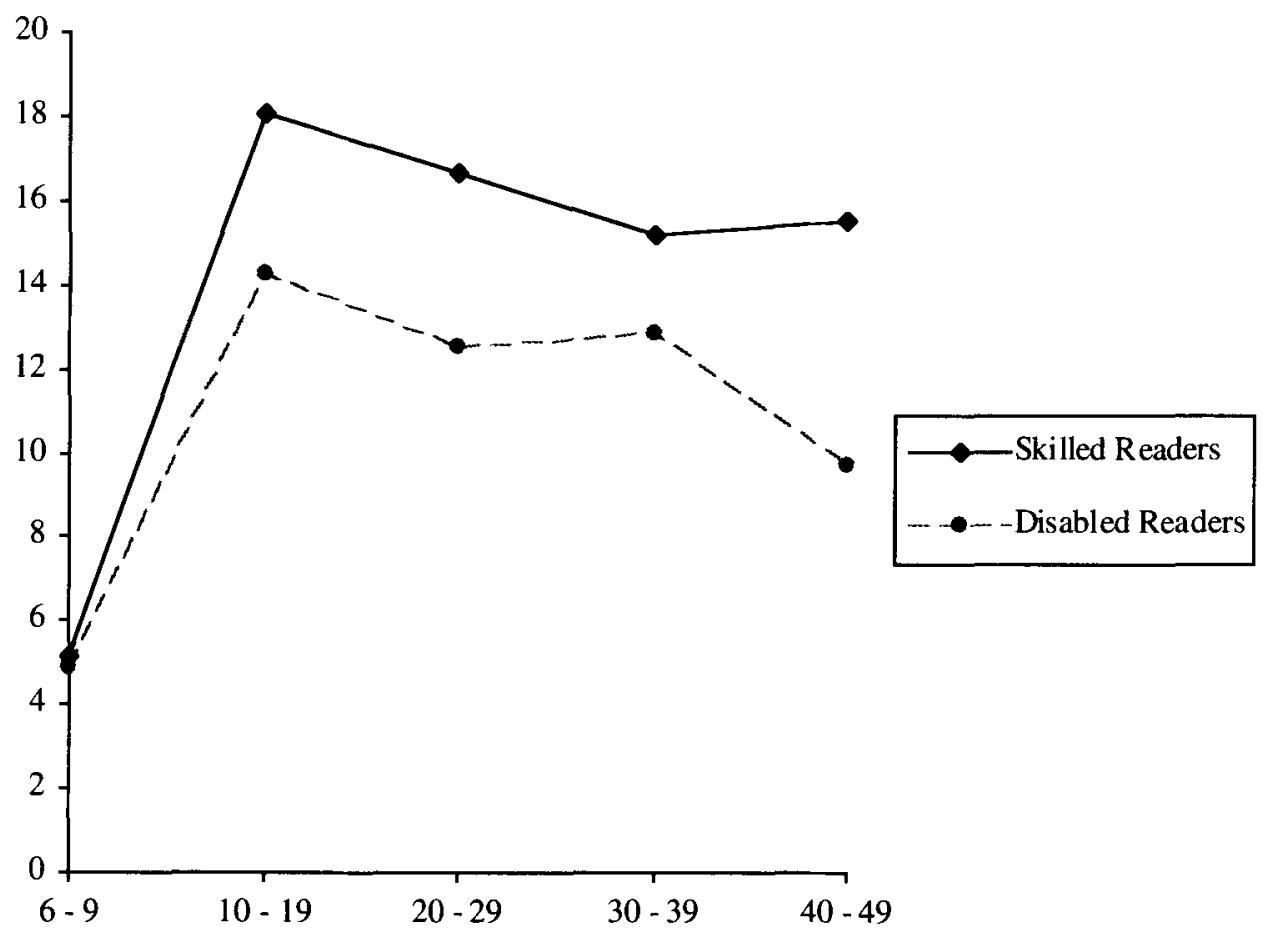

Figure 1. Absolute span scores as a function of age and reading skill on the blocked version of the working memory task.

that adolescents between the ages of 10 and 19 produced significantly fewer CNF intrusion errors than participants older than 29 . Skilled readers produced fewer CNF intrusions than disabled readers $[F(1,655)=15.82, p<$ .0011 . The age $\times$ reading group interaction was also significant $[F(4,655)=3.66, p<.01]$. The interaction was determined by a decline in CNF intrusions produced by skilled readers between the ages of 10 and 29 that was not shown by disabled readers.

Previous intrusions. The mean number of $P$ intrusions is shown in the upper portion of Table 1. The P intrusion rates did not differ significantly among the five age groups $[F(4,655)<1$, n.s.] or the two reading groups $[F(1,655)<1$, n.s. $]$. The age $\times$ reading group interaction was not significant $[F(4,655)<1$, n.s.].

Extraneous intrusions. The mean number of $E$ intrusions is shown in the two right columns in the top half of Table 1. There was a significant main effect of age $[F(4,655)=4.46, p<.01]$. Post hoc comparisons (Fischer's PLSD) indicated that children under the age of 10 produced significantly more $\mathrm{E}$ intrusion errors than did all the other participants. Skilled readers produced fewer $\mathrm{E}$ intrusions than did disabled readers $[F(1,655)=5.08$, $p<.01]$. The age $\times$ reading group interaction was not significant $[F(4,655)=1.24$, n.s.].

\section{Discussion}

At each age, skilled readers had higher listening span scores than did disabled readers. Thus, difficulties in working memory for disabled readers extend beyond childhood into adolescence and adulthood. These findings are consistent with the literature (Siegel, 1994). Deficits in inhibitory control may contribute to disabled readers' lower span scores. Overall, disabled readers produced more intrusion errors than skilled readers. In fact, CNF intrusions and $\mathrm{E}$ intrusions were particularly difficult for disabled readers, suggesting that disabled readers were less efficient in the access and restraint functions of inhibition. Deficits in the access and restraint functions of inhibition would permit irrelevant information increased entry into working memory. However, proactive interference, as indicated by $P$ intrusions, was not problematic for disabled readers. Thus, the current findings suggest that deficits in the access and restraint functions of inhibitory control may contribute to the difficulties experienced by disabled readers in working memory.

The current study revealed that working memory performance increased steadily through childhood and adolescence and then gradually declined after age 20 (which is consistent with Siegel, 1994). The results of the error analyses provided mixed support for the inhibitory control hypothesis. Adolescents between the ages of 10 and 19 produced fewer CNF errors (which would indicate failures in the access function of inhibition) than did adults older than 29. However, the significant interaction for the CNF errors suggests that disabled readers do not experience the increased efficiency in the access function of inhibition between the ages of 10 and 29 that is experienced by skilled readers. In contrast, the error patterns of the $P$ intrusions and $E$ intrusions did not support the inhibitory 
control hypothesis. In fact, there was no effect of age for the previous intrusions. Similarly, although young children produced more $E$ errors than adolescents and adults, participants older than 10 produced $E$ errors with comparable frequency. Thus, the error analysis suggests that only the access function of inhibitory control may account for the decline in working memory performance associated with aging.

\section{EXPERIMENT 2}

The data from Experiment 1 suggest that deficits in working memory performance associated with reading disability may result from inefficient inhibitory control. The deficits in the access and restraint functions of inhibitory control among individuals with reading disabilities were consistent with evidence of deficient suppression mechanisms among university students who were less skilled readers (Gernsbacher \& Faust, 1991; Gernsbacher et al., 1990). However, Experiment 1 provided limited support for the hypothesis that age-related declines in working memory performance were caused by deficits in inhibitory control. Although older adults showed impairments in the access function of inhibition, there was no relationship between aging and the deletion or restraint functions of inhibition. These results were surprising in light of other studies showing that the effects of proactive interference increase with age (e.g., Kane \& Hasher, 1996; May et al., 1996).

Another way of addressing the hypothesis that declines in working memory spans result from diminished inhibitory control is by changing the procedure for administering the working memory task. If declines in working memory are the result of deficient inhibitory control, then changing the procedure to minimize proactive interference should reduce age differences. In fact, Hasher and her colleagues eliminated age differences in working memory spans by making such alterations. For example, although adults aged 60 and older had lower span scores than young adults when span measures were presented in the typical ascending order, age differences completely disappeared when span measures were presented in descending order (May et al., 1996). Similarly, older adults' working memory spans were as large as those of young adults when the distinctiveness of each trial was enhanced by administering a 90 -sec nonverbal distractor task after each trial (May et al., 1996). Although deficits in inhibitory control may play an important role in working memory for adults over 60 , it is less clear whether such deficits influence the working memory performance of middle-aged adults. Similarly, it is less clear whether altering the procedure would benefit poor readers to the same extent as older adults.

The purpose of Experiment 2 was to further examine the role of inhibition in working memory. The role of inhibitory control was assessed in two ways. First, the inhibitory control hypothesis was tested by presenting the working memory span task using a mixed design in which three sets of trials each contained two, three, and four sentences. Because the inhibitory control hypothesis proposes that inhibition would be diminished for individuals susceptible to proactive interference when trials are distinctive, support for the inhibitory control hypothesis would take the form of diminished effects of aging on the span measure when the mixed design of the listening span was administered. In addition, the error analysis used in Experiment 1 was used to assess the role of inhibitory control in working memory.

\section{Method}

\section{Participants}

The analyses presented here are based on the combined data from adults and children who participated in one of a series of published and unpublished studies (e.g., Gottardo, Stanovich, \& Siegel, 1996; Siegel, 1994). This total sample included 331 individuals-- 137 skilled readers and 194 disabled readers. Participants from these studies had been recruited from schools, universities, colleges, and community agencies, or they were volunteers from the community. The sample was predominantly middle class. All participants had been educated in English. Participants were classified as reading disabled if they had scores below the 26th percentile on the WRAT (or the WRAT-R or the WRAT-3) and an IQ $>79$ on an abbreviated version of the WISC-R or the WAIS-R that included the Vocabulary and the Block Design subtests.

Participants were arbitrarily divided into five age groups: $6-9$, $10-19,20-29,30-39$, and $40-49$. The numbers of skilled readers (first number in parentheses) and disabled readers (second number in parentheses) within each age group were as follows: 6-9 (67, $127), 10-19(16,16), 20-29(18,19), 30-39(26,27)$, and $40-49$ $(10,5)$.

\section{Reading Tests}

The reading subtest of the WRAT (or the WRAT-R or the WRAT-3) was administered.

\section{Working Memory}

Gottardo et al.'s (1996) adaptation of Daneman and Carpenter's (1980) listening span task was used as the mixed design. Participants were required to listen to a series of sentences and decide whether each was true or false. After listening to each of the sentences in a set, participants attempted to recall the final word of each sentence in the set. As in the blocked design used in Experiment 1 , there were three trials containing two sentences, three trials with three sentences, and three trials with four sentences. However, unlike the blocked design, trials of the same length were not blocked. Instead, each of the three sets contained a two-item trial followed by a three-item trial, and ended with a four-item trial. An absolute span score was calculated for each participant using the procedure described in Experiment 1. The maximum score was 27.

\section{Error Analysis}

Errors on the listening span task were classified using the procedure outlined in Experiment 1. Using the procedures described above, the relative proportion of no response errors was calculated, as well as the raw scores for the total intrusions, CNF intrusions, $P$ intrusions, and $\mathrm{E}$ intrusions.

\section{Results}

The results for the absolute span scores are shown in the two left columns in the lower portion of Table 1 and in Figure 2. A 5 (age) $\times 2$ (reading group) ANOVA indicated significant main effects of reading group $[F(1,321)=$ 


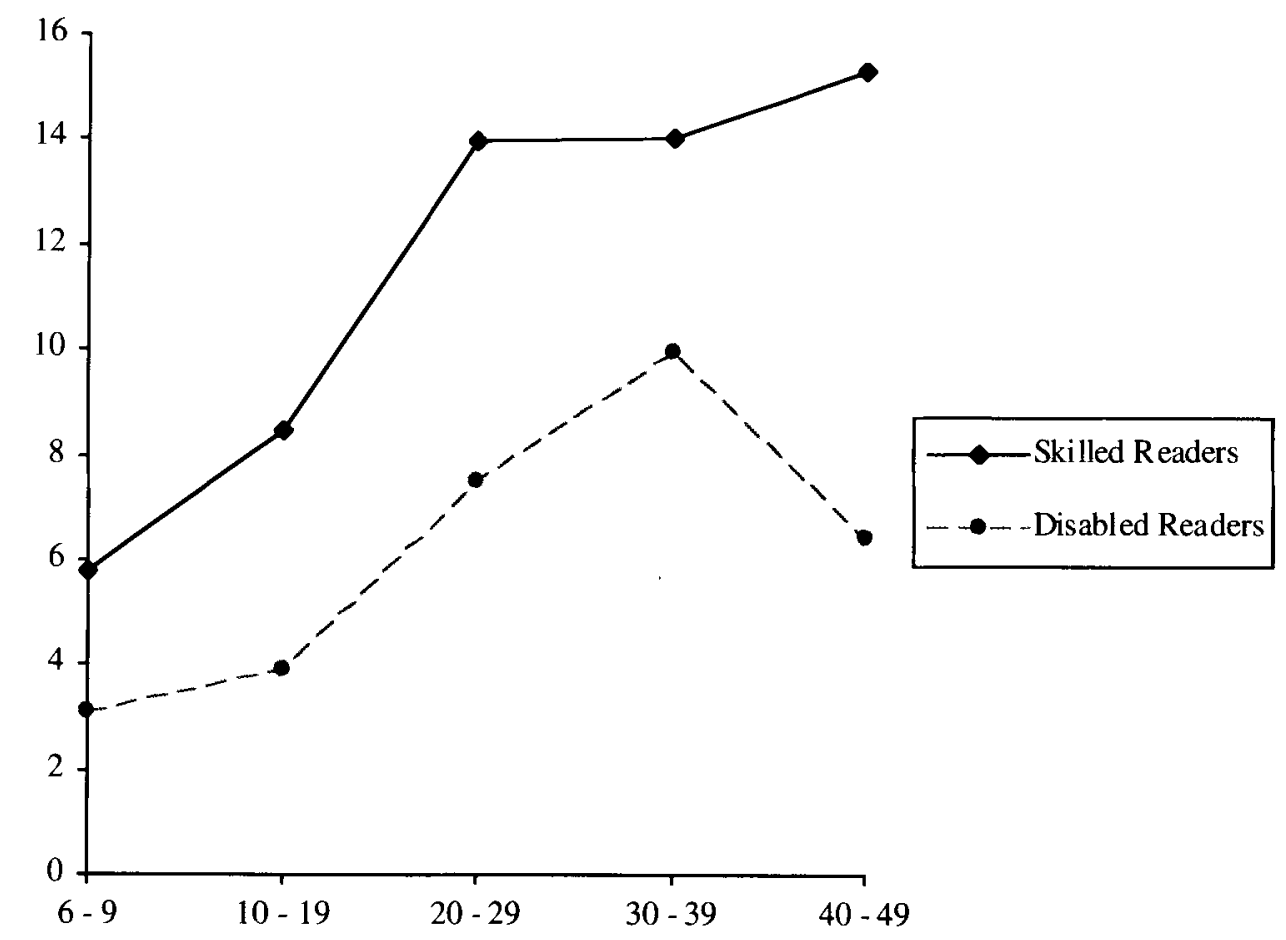

Figure 2. Absolute span scores as a function of age and reading skill on the mixed version of the working memory task.

$49.68, p<.001]$ and age $[F(4,321)=35.31, p<.001]$. The interaction between age and reading group was significant $[F(4,321)=2.42, p<.05]$. The mixed version of the working memory task revealed an increase in working memory capacity for both skilled and disabled readers throughout the life span. This pattern of performance is in contrast with the pattern revealed in Experiment 1 . Individual comparisons for each age group ( $t$ tests) indicated that skilled readers had higher scores than disabled readers at each age level. In general, there were significant differences between the first three adjacent age groups (under 10,10-19, and 20-29). The scores of children under 10 were significantly lower than those of the other groups, and the scores of the 10-19 age group were significantly lower than those of the 20-29, 30-39, and $40-49$ groups. The interaction was determined by both a greater increase in working memory performance for skilled readers than for disabled readers as they went from the youngest age group to the 10-19 group, and by a decline in performance seen in poor readers in the 40-49 age group. However, this decline was not shown by skilled readers. In sum, reading span scores increased with age for both skilled readers and disabled readers between the ages of 6 and 29. Thereafter, span scores leveled off for skilled readerś and declined for disabled readers.

\section{Error Analyses}

No responses. The proportion of no responses is shown in the lower half of Table 1. The proportion of no response errors was analyzed using a 5 (age) $\times 2$ (reading group) ANOVA. No response rates declined significantly across the five age groups $[F(4,317)=2.77, p<$ $.05]$. There was a tendency for skilled readers to produce a greater proportion of no responses $[F(1,317)=3.27$, $p<.07]$. The age $\times$ reading group interaction was not significant $[F(4,317)<1$, n.s.]. Post hoc comparisons (Fischer's PLSD) indicated that adults in the 30-39 group produced fewer no response errors than did children under 10 and adolescents $10-19$ years old.

Total intrusions. The mean number of intrusion errors is shown in the bottom half of Table 1. Disabled readers produced more intrusion errors than did skilled readers $[F(1,321)=24.41, p<.001]$. There were no significant differences among the age groups $[F(4,321)=1.59$, n.s. $]$, and the interaction between age and reading group was not significant $[F(4,321)<1$, n.s. $]$.

CNF. The mean number of CNF intrusions is shown in the lower portion of Table 1 . The mean number of CNF intrusions was analyzed using a 5 (age) $\times 2$ (reading group) ANOVA. Disabled readers produced more CNF intrusions than did skilled readers $[F(1,321)=27.03$, $p<.001]$. There were no significant differences among the age groups $[F(4,321)=1.28$, n.s. $]$, and the interaction between age and reading group was not significant $[F(4,321)<1$, n.s. $]$.

$P$ intrusions. The mean number of $P$ intrusions is shown in the lower portion of Table 1 . The $\mathrm{P}$ intrusion rates did not differ significantly among the five age groups 
$[F(4,321)<1$, n.s. $]$ or the two reading groups $[F(1,321)<$ 1 , n.s.]. The age $\times$ reading group interaction was not significant $[F(4,321)<1$, n.s. $]$.

$\mathbf{E}$ intrusions. The mean number of $\mathrm{E}$ intrusions is shown in the two right columns in the lower half of Table 1. Disabled readers produced more $\mathrm{E}$ intrusions than did skilled readers $[F(4,321)=5.47, p<.001]$. The main effect of age approached significance $[F(4,321)=2.96$, $p<.08]$. Post hoc comparisons (Fischer's PLSD) suggested that children under the age of 10 produced more $\mathrm{E}$ intrusions than adults between the ages of 20-49. The interaction was not significant $[F(4,321)=1.55$, n.s. $]$.

\section{Discussion}

Skilled readers consistently earned higher listening span scores than disabled readers. These results are consistent with the findings of Experiment 1 . The failure of the mixed design to eliminate differences between skilled readers and disabled readers suggests that disabled readers' deficits in working memory cannot be attributed to proactive interference. Further, there was no suggestion that disabled readers produced more $P$ intrusions than skilled readers, although $P$ intrusions are considered an index of proactive inhibition. Together, these two findings indicate that disabled readers' difficulties in working memory are not the result of deficits in the deletion function of inhibition. In contrast, individuals with reading disabilities demonstrated difficulties in both the access and the restraint functions of inhibition, since they produced more $\mathrm{CNF}$ and $\mathrm{E}$ errors than did skilled readers. These findings, which were convergent with those of Experiment 1 , suggest that disabled readers have difficulties in screening out irrelevant information. Thus, deficits in the access and restraint functions of inhibitory control may contribute to the lower listening span scores of disabled readers.

Although the standard blocked design used in Experiment 1 revealed that working memory performance increased steadily until adolescence, and then gradually declined after age 20 , the mixed design did not reveal such a decline, except for poor readers. In fact, with the mixed design of the working memory task, adults over the age of 19 had significantly higher span scores than children and adolescents. However, the span scores for each group of adults did not differ. These findings, together with those of May et al. (1996), suggest that proactive interference plays an important role in the decline of working memory performance associated with aging. Both the procedural changes used in the present study and the changes used by May et al. (1996) demonstrated that working memory spans would not decline with age if proactive interference was minimized. Similarly, the results of the error analyses suggest that the mixed design reduced differences associated with aging with respect to the role of inhibition in working memory. In fact, none of the error categories revealed evidence for the decline in inhibitory control associated with aging using the mixed design.
Therefore, decreases in working memory associated with aging might be attributed to declines in inhibitory control rather than declines in capacity.

\section{GENERAL DISCUSSION}

The current study investigated the role of proactive interference in working memory in two main ways. The role of inhibitory control was considered in relation to reading skill and in relation to age. Each will be discussed in turn.

At each age, there were differences between skilled and disabled readers on the working memory tasks, suggesting that difficulties in working memory for disabled readers extend beyond childhood into adolescence and adulthood. The finding of a persistent working memory deficit through the life span of disabled readers is consistent with the literature (Siegel, 1994). Deficient suppression mechanisms control may have contributed to disabled readers' lower span scores. In fact, both the standard blocked and mixed designs of the listening span task revealed deficits in the access and restraint functions of inhibitory control among disabled readers. That is, disabled readers had greater difficulty in preventing irrelevant information from entering working memory. However, disabled readers' impairments in inhibition did not include greater susceptibility to proactive interference. For example, although the mixed design was expected to reduce the influence of proactive interference on memory span, differences between skilled readers and disabled readers remained. Similarly, disabled readers did not have difficulties with the deletion functions of inhibitory control, as indicated by the fact that they produced previous final word intrusions with the same frequency as skilled readers. Therefore, the current study extends evidence of deficient suppression mechanisms among normally achieving university students who are less skilled comprehenders (e.g., Gernsbacher \& Faust, 1991; Gernsbacher \& Robertson, 1995; Gernsbacher et al., 1990; Whitney et al., 1991) to populations of individuals with reading disabilities.

The two working memory tasks revealed very different patterns in terms of the declines in working memory associated with aging from adolescence to midlife. Although both designs showed increases in performance with increasing age through childhood and adolescence, the patterns of performance diverged in adulthood. The blocked design showed a decline after age 20 (which is consistent with Siegel, 1994), whereas the mixed design did not. Similarly, the absence of age effects in the error data in Experiment 2 suggest that the mixed design reduced the effects of inhibition. These findings suggest the importance of inhibitory control for older adults. Simply changing the procedure of the listening span to diminish proactive interference resulted in improved performance for middle-aged adults as well as young adults. Thus, the span data are consistent with other studies suggesting that declines in working memory reported for older adults 
may result from difficulties in inhibiting irrelevant information rather than declines in working memory capacity (Hartman \& Hasher, 1991; Hasher \& Zacks, 1988; Hasher et al., 1999; May et al., 1996).

However, the error analyses using the blocked format of the working memory task provided only mixed support for the relation between inhibitory control and aging. The error patterns revealed for the CNF intrusions, which were hypothesized to reflect failures in the access function of inhibition, were consistent with the inhibitory control hypothesis. The greater frequency of CNF intrusions among participants older than 29 suggests that the older adults experienced greater difficulties in preventing goal-irrelevant information from entering working memory. However, the relationship between the efficiency of the access function of inhibitory control and age was restricted to skilled readers. The frequency of CNF errors was unrelated to age among disabled readers, who showed general impairments in denying goal-irrelevant information access into working memory. In contrast, although $P$ intrusions were hypothesized to reflect failures in the deletion function of inhibition and to lead to proactive interference, older adults produced as many $P$ intrusion errors as younger participants did in both experiments. These findings are surprising in light of other studies that have shown greater susceptibility to proactive interference in older adults (e.g., Kane \& Hasher, 1996). Finally, there was little evidence of declines in the restraint function of inhibition. Therefore, the errors produced using the blocked design provided evidence for the hypothesis that decreases in working memory associated with aging may be attributed to declines in the access function of inhibitory control rather than declines in capacity.

In summary, deficits in working memory are characteristic of disabled readers throughout the life span. Working memory skills develop through childhood and adolescence; however, the standard blocked design revealed declines in middle adulthood whereas the mixed design did not. The different patterns suggest that the decline in working memory skills associated with aging may result from growing inefficiencies in inhibitory control rather than diminished capacity. These declines were associated with growing inefficiencies in the access function of inhibition. In contrast, disabled readers' difficulties in working memory result from smaller working memory capacity in addition to difficulties in restricting access to the working memory system to relevant information.

\section{REFERENCES}

Babcock, R. L., \& Salthouse, T. A. (1990). Effects of increased demands on age differences in working memory. Psychology \& Aging, $5,421-428$.

Baddeley, A. D. (1983). Working memory. Philosophical Transactions of the Royal Society of London: Series $B, \mathbf{3 0 2}, 311-324$.

BADDELEY, A. D. (1986). Working memory. London: Oxford University Press.

BrUCK, M. (1990). Word-recognition skills of adults with childhood diagnoses of dyslexia. Developmental Psychology, 26, 439-454.
Bruck, M. (1992). Persistence of dyslexics' phonological awareness deficits. Developmental Psychology, 28, 874-886.

Bruck, M., \& Treiman, R. (1990). Phonological awareness and spelling in normal children and dyslexics: The case of initial consonant clusters. Journal of Experimental Child Psychology, 50, 156178.

Campbell, J. I. D., \& Charness, N. (1990). Age-related declines in working-memory skills: Evidence from a complex calculation task. Developmental Psychology, 26, 879-888.

Case, R., Kurland, D. M., \& GoldberG, J. (1982). Operational efficiency and the growth of short-term memory span. Journal of $E_{x}$ perimental Child Psychology, 28, 386-404.

ChIAPPE, P., \& SiEgel, L. S. (1999). Phonological awareness and reading acquisition in English and Punjabi-speaking Canadian children. Journal of Educational Psychology, 91, 20-28.

Da Fontoura, H. A., \& Siegel, L. S. (1995). Reading, syntactic, and working memory skills of bilingual Portuguese-English Canadian children. Reading \& Writing: An Interdisciplinary Journal, 7, 139153.

Daneman, M., \& Carpenter, P. A. (1980). Individual differences in working memory and reading. Journal of Verbal Learning \& Verbal Behavior, 19, 450-466.

De Beni, R., Palladino, P., Pazzaglia, F., \& Cornoldi, C. (1998). Increases in intrusion errors and working memory deficit of poor comprehenders. Quarterly Journal of Experimental Psychology, 51 A, 305-320.

Engle, R. W., Cantor, J., \& Carullo, J. J. (1992). Individual differences in working memory and comprehension: A test of four hypotheses. Journal of Experimental Psychology: Learning. Memory. \& Cognition, 18, 972-992.

Engle, R. W., Nations, J. K., \& Cantor, J. (1990). Is "working memory capacity" just another name for word knowledge? Journal of Educational Psychology, 82, 799-804.

GERNSBACHER, M. A. (1990). Language comprehension as structure building. Hillsdale, NJ: Erlbaum.

Gernsbacher, M. A., \& Faust, M. E. (1991). The mechanism of suppression: A component of general comprehension skill. Journal of Experimental Psychology: Learning, Memory, \& Cognition, 17, 245262.

Gernsbacher, M. A., \& Robertson, R. R. W. (1995). Reading skill and suppression revisited. Psychological Science, 6, 165-169.

Gernsbacher, M. A., Varner, K. R., \& Faust, M. E. (1990). Investigating differences in general comprehension skill. Journal of Experimental Psychology: Learning, Memory, \& Cognition, 16, 430-445.

Geva, E., \& SiEGEL, L. S. (in press). The role of orthography and cognitive factors in the concurrent development of basic reading skills in bilingual children. Reading \& Writing: An Interdisciplinary Journal.

Gick, M. L., Craik, F. I. M., \& Morris, R. G. (1988). Task complexity and age differences in working memory. Memory \& Cognition, 16, 353-361.

Gottardo, A., Stanovich, K. E., \& Siegel, L. S. (1996). The relationships between phonological sensitivity, syntactic processing, and verbal working memory in the reading performance of third-grade children. Journal of Experimental Child Psychology, 63, 563-582.

HaMM, V. P., \& Hasher, L. (1992). Age and the availability of inferences. Psychology \& Aging, 7, 56-64.

Hartman, M., \& Hasher, L. (1991). Aging and suppression: Memory for previously relevant information. Psychology \& Aging, 6, 587-594.

Hasher, L., Stoltzfus, E. R., Rumpa, B., \& Zacks, R. T. (1991). Age and inhibition. Journal of Experimental Psychology: Learning, Memory, \& Cognition, 17, 163-169.

HASHER, L., \& ZACKS, R. T. (1988). Working memory, comprehension, and aging: A review and new view. In G. H. Bower (Ed.), The psychology of learning and motivation (Vol. 22, pp. 193-225). San Diego: Academic Press.

Hasher, L., ZaCks, R. T., \& MAY, C. P. (1999). Inhibitory control, circadian arousal, and age. In D. Gopher \& A. Koriat (Eds.), Attention and performance XVII: Cognitive regulation of performance: Interaction of theory and application (pp. 653-675). Cambridge, MA: MIT Press. 
Hitch, G. J., \& HaLliday, M. S, (1983). Working memory in children. Philosophical Transactions of the Royal Society of London: Series B, 302, 325-340.

JASTAK, J, R., \& JASTAK, S. R. (1978). Wide range achievement test. Wilmington, DE: Jastak Associates.

JASTAK, S., \& WILKINSON, G. S. (1984). Wide range achievement testrevised. Wilmington, DE: Jastak Associates.

KANE, M. J., \& HASHER, L. (1996). Interference. In G. Maddox (Ed.), Encyclopedia of aging (2nd ed.). New York: Springer-Verlag.

Kane, M. J., May, C. P., Hasher, L., \& RahHal, T. (1997). Dual mechanisms of negative priming. Journal of Experimental Psychology: Human Perception \& Performance, 23, 632-650.

LIGHT, L. L., \& ANDERson, P. A. (1985). Working-memory capacity, age, and memory for discourse. Journal of Gerontology, 40, 737-747.

MaY, C. P., Kane, M. J., \& HaSher, L. (1995). Determinants of negative priming. Psychological Bulletin, 118, 35-54.

May, C. P.. Kane, M. J., Hasher, L., \& Valenti, M. (1996, November) Proactive interference and working memory span. Paper presented at the annual meeting of the Psychonomic Society, Chicago.

Morris, R. G., Gick, M. L., \& Craik, F. I. M. (1988). Processing resources and age differences in working memory. Memory \& Cognition, 16, 362-366

Perfetti, C. A. (1985). Reading ability. New York: Oxford University Press.

RaCk, J. P., SNOwling, M. J., \& Olson, R. K. (1992). The nonword reading deficit in developmental dyslexia: A review. Reading Research Quarterly, 27, 28-53.

Salthouse, T. A., \& Babcock, R. L. (1991). Decomposing age differences in working memory. Developmental Psychology, 27, 763-776.

SATTLER, J. M. (1982). Assessment of children 's intelligence and special abilities (3rd ed.). Boston: Allyn \& Bacon.

Shafrir, U., \& SiEgel, L. S. (1992). Subtypes of learning disabilities in adolescents and adults. Unpublished manuscript, Ontario Institute for Studies in Education, Toronto.

Share, D. L. (1995). Phonological recoding and self-teaching: Sine que non of reading acquisition. Cognition, 55, 151-218

SIEGEL, L. S. (1994). Working memory and reading: A life-span perspective. International Journal of Behavioral Development, 17, 109 124.

Siegel, L. S., \& Linder, B. A. (1984). Short-term memory processes in children with reading and arithmetic learning disabilities. Developmental Psychology, 24, 28-37.

SiEGEL. L. S., \& RYAN, E. B. (1988). Development of grammatical sensitivity, phonological, and short-term memory skills in normally achieving and learning disabled children. Developmental Psychologv, 24, 28-37.
Silverstein, A. B. (1982). Two- and four-subtest short forms of the Wechsler Adult Intelligence Scale-Revised. Journal of Counselling \& Clinical Psychology, 50, 415-418

So, D., \& SiegEL, L. S. (1997). Learning to read Chinese: Semantic, syntactic, phonological and short-term memory skills in normally achieving and poor Chinese readers. Reading \& Writing: An Interdisciplinary Journal, 9, 1-21.

Stanovich, K. E. (1986). Matthew effects in reading: Some consequences of individual differences in the acquisition of literacy. Reading Research Quarterly, 21, 360-407.

Stanovich, K. E., \& Siegel, L. S. (1994). Phenotypic performance profile of children with reading disabilities: A regression-based test of the phonological-core variable-difference model. Journal of Educational Psychology, 86, 24-53.

Stoltzfus, E. R., Hasher, L., Zacks, R. T., Ulivi, M. S., \& GoldSTEIN, D. (1993). Investigations of inhibition and interference in younger and older adults. Journal of Gerontology: Psychological Sciences, 48, 179-188.

SWANSON, H. L. (1993). Individual differences in working memory: A model testing and subgroup analysis of learning-disabled and skilled readers. Intelligence, 17, 285-332.

SWANSON, H. L. (1994). Short-term memory and working memory: Do both contribute to our understanding of academic achievement in children and adults with learning disabilities? Journal of Learning Disabilities, 27, 34-50.

TirRe, W. C., \& PEÑA, C. M. (1992). Investigation of functional working memory in the reading span test. Journal of Educational Psychology, 84, 462-472.

WECHSLER, D. (1974). Manual for the Wechsler intelligence scale for children-Revised. New York: Psychological Corp.

WECHSLER, D. (1981). Manual for the Wechsler adult intelligence scaleRevised. New York: Psychological Corp.

WhitNey, P., Ritchie, B. G., \& ClaRK, M. B. (1991). Working-memory capacity and the use of elaborative inferences in text comprehension. Discourse Processes, 14, 133-146.

WILKINSON, G. S. (1994). Wide range achievement test-3. Wilmington, DE: Jastak Associates.

Wingfield, A., Stine, E., Lahar, C. J., \& Aberdeen, J. S. (1988). Does the capacity of working memory change with age? Experimental Aging Research, 14, 103-107.

ZACKS, R. T., \& HASHER, L. (1988). Capacity theory and the processing of inferences. In L. L. Light \& D. M. Burke (Eds.), Language, memory and aging (pp. 154-170). New York: Cambridge University Press.

(Manuscript received September 30, 1997; revision accepted for publication December 25, 1998.) 